\title{
Bidding behavior in the bisection auction : an experimental investigation
}

Citation for published version (APA):

Grigorieva, E., \& Strobel, M. (2006). Bidding behavior in the bisection auction : an experimental investigation. METEOR, Maastricht University School of Business and Economics. METEOR Research Memorandum No. 026 https://doi.org/10.26481/umamet.2006026

Document status and date:

Published: 01/01/2006

DOI:

10.26481/umamet.2006026

Document Version:

Publisher's PDF, also known as Version of record

\section{Please check the document version of this publication:}

- A submitted manuscript is the version of the article upon submission and before peer-review. There can be important differences between the submitted version and the official published version of record.

People interested in the research are advised to contact the author for the final version of the publication, or visit the DOI to the publisher's website.

- The final author version and the galley proof are versions of the publication after peer review.

- The final published version features the final layout of the paper including the volume, issue and page numbers.

Link to publication

\footnotetext{
General rights rights.

- You may freely distribute the URL identifying the publication in the public portal. please follow below link for the End User Agreement:

www.umlib.nl/taverne-license

Take down policy

If you believe that this document breaches copyright please contact us at:

repository@maastrichtuniversity.nl

providing details and we will investigate your claim.
}

Copyright and moral rights for the publications made accessible in the public portal are retained by the authors and/or other copyright owners and it is a condition of accessing publications that users recognise and abide by the legal requirements associated with these

- Users may download and print one copy of any publication from the public portal for the purpose of private study or research.

- You may not further distribute the material or use it for any profit-making activity or commercial gain

If the publication is distributed under the terms of Article $25 \mathrm{fa}$ of the Dutch Copyright Act, indicated by the "Taverne" license above, 


\section{Elena Grigorieva, Martin Strobel}

Bidding behavior in the bisection auction - an experimental investigation

$\mathrm{RM} / 06 / 026$

JEL code: C91, D44

\section{METE@R}

Maastricht research school of Economics of TEchnology and ORganizations

Universiteit Maastricht

Faculty of Economics and Business Administration P.O. Box 616

NL - 6200 MD Maastricht

phone : :++31433883830

fax $\quad$ : ++31433884873 



\title{
Bidding behavior in the bisection auction - an experimental investigation
}

\author{
Elena Grigorieva * MARtin Strobel $^{\dagger}$
}

June 20, 2006

\begin{abstract}
We present a laboratory experiment in which we investigate bidding behavior with independent private values in the recently proposed bisection auction, and compare it with two classical auction formats - the Vickrey auction and the English auction. We test whether subjects behave strategically equivalent, following the dominant truth-telling strategy, as predicted by theory. Furthermore, we provide some insights concerning the learning process, the efficiency of allocation, and the revenue to the auctioneer. The data show that the bisection auction performs better than the Vickrey auction and only in some terms worse than the English auction.
\end{abstract}

JEL Codes. D44, C91.

Keywords. experiment, auction, private value, Vickrey auction, English auction, bisection auction, strategic equivalence.

\section{Introduction}

A well known theoretical result for private value single item auctions is the strategic equivalence of the sealed bid second-price auction and the English auction. This result was shown by Vickrey ${ }^{1}$ in his seminal 1961 contribution to auction theory [12]. Strategic equivalence of these two auctions implies that, as long as bidders behave rationally, the same bidder wins and pays the same price. Two main results were established: first of all, truth-telling is a weakly dominant strategy, independent of the a-priori distribution of the valuations of the bidders, the number of bidders or their risk attitudes. Secondly, the

*e.grigorieva@ke.unimaas.nl. Department of Quantitative Economics, Maastricht University, P.O. Box 616, 6200 MD Maastricht, The Netherlands.

${ }^{\dagger}$ m.strobel@algec.unimaas.nl. Department of Economics, Universiteit Maastricht, P.O. Box 616, 6200 MD Maastricht, The Netherlands.

${ }^{1}$ For this reason the sealed bid second price auction also known nowadays as the Vickrey auction. 
resulting truth-telling equilibrium is efficient in the sense that the object gets assigned to the bidder who values it most.

Yet both the Vickrey auction and the English auction have their drawbacks in practical use. As any direct mechanism the Vickrey auction requires all participants to reveal complete and exact preference information. Buyers might be reluctant to truthfully reveal their full private value if its revelation could have a negative strategic long-term impact [10]. For example, after such an auction the buyer will be at a disadvantage in future negotiations with the seller who may be able to extract more surplus in the future using information about the buyer's valuation.

A significant problem with the English auction is that it might proceed at a very slow pace, if very small price increments is chosen. This shortcoming can be devastating, for instance, when using auctions to allocate highly perishable resources in real-time, like network capacities or electric power. One remedy is to introduce a minimum or a fixed bid increment, as has been done for example in the spectrum auctions. This though is known to have a negative impact on the auction's efficiency [2].

The question that arises is: how to design an auction that elicits less information about bidders' valuations than the Vickrey auction but still enough to guarantee an efficient allocation and which is at the same time faster than the English auction. In [5] a new iterative auction that possesses these properties, called the bisection auction, is introduced. The main idea of this auction is to search for the winner (the player with the highest valuation) and the price (the second highest valuation) using the bisection method. The auction consists of several rounds in each of which the auctioneer announces a price and players report their demand. Depending on the players' answers the price of the next round can increase or decrease and some players can be eliminated from the auction. The precise description of the auction rules will be given in Section 2 .

Grigorieva et al. show that the bisection auction is strategically equivalent to the Vickrey auction (and hence also to the English auction) [5]. Therefore it preserves efficiency and has truth-telling as a dominant strategy. While being strategically equivalent to the Vickrey and English auctions the bisection auction outperforms them in terms of speed and valuation revelation requirement. Contrary to the English auction the bisection procedure guarantees a fast and predictable termination of the proposed auction. In comparison with the Vickrey auction, the bisection auction requires much less information to be revealed to the auctioneer. Through incremental querying the auctioneer asks bidders for very limited information about their valuation, namely whether the valuation is more than an asked price or not. Information already revealed guides the selection of subsequent queries in such a way that only pertinent 
information is asked. As soon as it becomes clear to the auctioneer that a particular bidder doesn't possess relevant information, i.e information which helps the auctioneer to find the winner and the price, this bidder is eliminated from the auction. An optimal outcome is determined despite the fact that almost all bidders' valuations have only been partially revealed. Only the bidder with the second highest valuation reveals it entirely, something that is inevitable in a Vickrey implementation [4].

Given the advantages of the bisection auction, it seems strange that one does not come across it in practical applications. One potential reason is that while all three auctions are theoretically equivalent, they might differ substantially from a behavioral point of view when boundedly rational decision makers are involved. Several experiments were conducted so far for testing the strategic equivalence of the Vickrey and English auctions in the laboratory. The results by and large show that in contrast with theory players typically do not behave in an equivalent way. Behavior according to the dominant truthtelling strategy was observed more often in the English auction (see e.g [1] and [7]). In the Vickrey auction, observed bids often exceeded the predicted level ([6], [7] and [8]). As conjectured in [9], this difference in behavior can be attributed to different information flows inherent in the structure of the two auctions. The structure of the English auction makes it relatively transparent to players that they should not bid above their valuations - any time a player bids above his valuation and wins he necessarily loses money. In contrast, in the Vickrey auction there is no such direct link between the bid of a winner and the price he has to pay. In the Vickrey auction a player does not necessarily lose money if he bids above his private valuation and wins. This sustains the illusion that overbidding improves the probability of winning with only the little risk of paying a price above the own valuation. The feedback mechanism to learn and to correct overbidding is therefore weaker in the Vickrey procedure.

The reported breakdown of the strategic equivalence of the Vickrey and English auctions with respect to behavior raises justified doubts on the behavioral equivalence of the bisection auction and the others. The bisection auction due to its more complicated rules seems to be more difficult to understand. An particularly uncommon feature for auctions is that the price is moving up and down. It might make bidders think that with bidding high initially and hoping that the price would go down later in the auction, they can increase their profit by overbidding. In this sense the bisection auction also lacks the tight cognitive connection between probability to win and the price to be paid. The situation calls for an initial test of behavioral equivalence before putting the bisection mechanism to practice. One could argue, that market forces will drive out irrational behavior and will lead to the dominant strategy behavior sooner or later. The process, however, will not be free of frictions (e.g. law suits) and thus a good ex-ante estimate of the behavioral anomalies in the bisection auction will be helpful. The goal 
of this paper is to make some first steps into the investigation of the practical usage of the bisection auction. Therefore we test all three auction types in a laboratory experiment and compare them with respect to truth-bidding, revenue and efficiency.

In comparison to the other auctions the bisection auction did fairly well and much better than we initially expected. The performance is quite comparable to the English auction and in terms of some measurements better than the Vickrey auction.

The paper is organized as follows. Section 2 briefly introduces the rules of the bisection auction. Section 3 describes the experimental design and laboratory procedure. Section 4 reports the results and tests and Section 5 concludes with a summary and some open questions. In the appendix the instructions, the post-experimental questionnaire and additional tables with relevant data are presented.

\section{The bisection auction}

Suppose a single indivisible object is auctioned. The buyers' valuations are supposed to be integer, randomly drawn from a bounded interval ${ }^{2}$ - by default of the form $\left[0,2^{R}\right)$ for some positive integer $R$. The bisection auction has $R$ rounds. The price sequence starts at the middle of the initial interval with a price equal to $2^{R-1}$. Bidders report their demand at the current price by sealed bids. Yes stands for the announcement to be willing to buy at the current price, no for the contrary. As a function of these bids, the auctioneer announces the price of the next round.

In case there are at least two players submitting a yes-bid, the price goes up to the middle of the upper half interval, i.e. to the interval $\left[2^{R-1}, 2^{R}\right)$. The players that are allowed to participate actively in the next round are the ones that submitted yes. In case there is at most one player submitting yes, attention shifts to the lower half interval, i.e. the interval $\left[0,2^{R-1}\right)$ and the price goes down to the middle of this interval. The active players in the next round are the ones that submitted no. In case there is a single buyer that submitted yes, this buyer becomes the winner and gets the object. Nevertheless the auction doesn't end, but continues. The winner, although he is no longer active, is considered to submit yes to all prices that are proposed beyond the moment he became the winner. ${ }^{3}$ Iterating this procedure will eventually yield a winner and a price. If in no round a winner was determined then ties are broken by random assignment to a player who is still active after $R$ rounds.

\footnotetext{
${ }^{2}$ For the generalization of the bisection auction for the setting of unbounded interval (which is a case if the auctioneer is ignorant concerning the upper bound on the valuations) see [5].

${ }^{3}$ After all, all these prices will be lower than the price he agreed to when he became the winner.
} 
The price is uniquely determined because in each round the length of the current interval goes down by one half. Since the initial interval is of length $2^{R}$, after $R$ rounds the resulting interval is of length 1 . And since it is a half-open interval, it contains exactly one integer. This integer is declared to be the price the winner of the auction has to pay for the object.

Example: Suppose there are four bidders, A, B, C, and D, with the following integer private valuations from the interval $[0,16): v_{A}=11, v_{B}=4, v_{C}=15, v_{D}=9$. To determine the winner and the price in this setting the bisection auction takes four rounds and starts with an ask price equal to $p=8$. Suppose that each bidder chooses to respond truthfully and follows a straightforward strategy under which he submits yes if an ask price is less or equal to his valuation and no otherwise. Bidders are not informed about other bidders' choices. The bisection auction proceeds as follows:

\begin{tabular}{cccccccc}
\hline Round & Price & $\begin{array}{c}\text { Lower } \\
\text { bound }\end{array}$ & $\begin{array}{c}\text { Upper } \\
\text { bound }\end{array}$ & $\begin{array}{c}\text { Bidder A } \\
v_{A}=11\end{array}$ & $\begin{array}{c}\text { Bidder B } \\
v_{B}=4\end{array}$ & $\begin{array}{c}\text { Bidder C } \\
v_{C}=15\end{array}$ & $\begin{array}{c}\text { Bidder D } \\
v_{D}=9\end{array}$ \\
\hline 1 & 8 & 0 & 16 & yes & no & yes & yes \\
2 & 12 & 8 & 16 & no & $($ no $)$ & yes & no \\
3 & 10 & 8 & 12 & yes & $($ no $)$ & $($ yes $)$ & no \\
4 & 11 & 10 & 12 & yes & $($ no $)$ & (yes $)$ & (no) \\
\hline
\end{tabular}

Since three bidders submitted yes in the first round, the price increases to the middle of the current price and the current upper bound. So the ask price of the second round is 12 . These three bidders remain active while bidder B drops out. Since there is only one yes submitted in the second round we have a winner and we enter what we call the price determination phase. From now on, any bid of the winner, bidder $\mathrm{C}$, is considered as a yes-bid. Players $\mathrm{A}$ and $\mathrm{D}$ are still active. In the third round, there are two yes-submissions (bidders A and C) so the price increases. ${ }^{4}$ Player D drops out. In the fourth round, the auction terminates. Taking into account bids made during the last round we compute the final lower and upper bounds. Since there were 2 yes-bids the upper bound remains to be 12 while the lower bound becomes 11. The winner, bidder $\mathrm{C}$, takes the object and pays price 11 which is the smallest Walrasian price for the demand announced by the bidders that participated in this auction.

\section{Experimental design and procedure}

To compare the auction mechanisms we designed an experiment with three different treatments VA, EA and BA which correspond to the Vickrey, English and bisection auction, respectively. The experiment

\footnotetext{
${ }^{4}$ Note that players $\mathrm{A}$ and $\mathrm{D}$ do not know that the winner is already determined. Moreover they are not able to derive this information from price movements. Given this lack of information they have still the incentive to bid truthfully.
} 
was computerized with the help of zTree [3]. Throughout the experiment we used ECU (Experimental Currency Unit) as a fictitious currency for expressing prices values, bids and earnings. One session lasted for 10 periods and was played by 9 subjects. In each period they were randomly partitioned into three groups of three bidders. At the beginning of each period every bidder got to know privately her value which was independently drawn from the uniform distribution over the interval [32,96). For every session of one treatment a new set of valuations and a new matching scheme were randomly generated. However, in order to maximize comparability of treatments we used the same sets of valuations and the same matching schemes across treatments. After learning their value subjects had to bid against the other group members in order to win the auction. The auction mechanism depended on the treatment.

Vickrey auction (VA): Subjects were asked to submit one bid which had to be an integer number from the interval $[0,128)$. The subject with the highest bid won the auction and received the object (i.e. she got her private value). The price the winner had to pay was equal to the second-highest bid that was made within the group.

English auction (EA): The English auction was implemented by using an ascending clock procedure. The price started at zero and increased continuously at a rate of 1 ECU per 2 seconds with the maximum possible price of 127 . Subjects had drop out at the price they were not willing to bid anymore. Dropping out was irrevocable so that a bidder could no longer bid on the object. The last bidder of the group won the object at the price 1 ECU below the price where the next-to-last bidder dropped out. ${ }^{5}$

Bisection auction (BA): The initial interval for the bisection auction was [0,128). The initial ask price was set to 64 . The winner and the price were then determined by the procedure described in section 2.

In all treatments ties could happen if at least two persons show exactly the same behavior and end up to be the "highest" bidders. In such cases the winner was randomly determined among the tied bidders. At the end of each period the winner of the auction received his private value but had to pay the determined final auction price. Each of the bidders was informed whether or not she bought the object, the selling price of the object, as well as her gains and losses.

The experiment was conducted in the experimental behavior laboratory of the economic faculty at Maas-

\footnotetext{
${ }^{5}$ We explicitly have chosen this instead of the classical version of the ascending clock English procedure where the winner gets the object at the price when the next-to-last bidder dropped out. This choice allowed us to simplify the part of the subjects instructions where we explained the moment of dropping out, namely "... at the price you are not willing to bid any more". This change in rules has the consequences that in the implemented version dropping out as soon as the price exceeded the private value is the dominant truth-telling strategy. Apart from that, these two versions are identical and either of them can be used for comparison with the bisection and Vickrey procedures.
} 
tricht University. In total 135 subjects took place in the experiment. Most of them were undergraduate students from economics or business. They could register for the experiment via Internet via their student id. By this we prevented double registration. In total we conducted 5 sessions for each treatment, with 9 subjects each. When subjects arrived at the laboratory they were randomly placed at isolated computer terminals, so that they neither could see screens of the others nor get into eye contact with them. The sessions lasted for about 60 minutes.

Before the start of a session subjects received written instructions (see Appendix 1). They were allowed to privately ask questions which were also privately answered by the experimenters. As a part of the instructions subjects were provided with examples of players' valuations and were asked to calculate the profit of each player for some assumed outcomes. The calculations were privately checked. The experiment started only when every calculation was done correctly. After a session we asked participants to fill in a post-experimental questionnaire (see the Appendix 2) where they could explain how they made their decisions and give any comments on the experiment.

Each participant received an initial endowment of 3 EURO. At the end of the experiment the amount which was earned was converted from ECU into Euro at the rate of 1 EURO $=4.5 \mathrm{ECU}$. For the case that the earned amount was negative, the losses were deducted from the initial endowment. Average earnings of the participants were about 13 Euro.

\section{Experimental results}

By and large we were able to replicate the common results on the Vickrey and the English auction. ${ }^{6}$ The data further shows that the bisection auction does not perform worse than the Vickrey auction. In some aspects it was doing better and matches the performance of the English auction. In the following we will analyze the data in more detail with respect to truth-bidding, learning, auctioneer's revenue and efficiency. If not mentioned explicitly we will base our statistical tests on the session level (i.e. on statistically independent observations). Therefore we aggregate the data by averaging over all observations within a session.

\footnotetext{
${ }^{6}$ See also our discussion in the introduction.
} 


\subsection{Bidding behavior}

Theory predicts bidders in all auctions types to follow a truth-telling strategy. In the following we check whether this is indeed the case or whether subjects tend to under- or overbid. When classifying subjects as truth-tellers we accept small deviations from the private value and call it a value bid. A reasons for small deviations could be that subjects ignored the possibility of ties. In such cases small deviations (i.e. by 1 ECU) from true-value bidding do not change the subjective expected payoff. Another reason for dropping out a bit too early or too late in the English auction could be the fear of missing the exact time to drop out or indeed missing it. In the following paragraphs we define value bids in detail and report results for the different treatments.

Vickrey auction: For VA truth-telling means to bid exactly the private value $v_{i}$, hence we consider any bid in the set $\left\{v_{i}-1, v_{i}, v_{i}+1\right\}$ as a value bid. If the bid was above or below this set we consider it as over- or underbidding, respectively.

The data shows that $48 \%$ of all 450 Vickrey bids are value bids while $30 \%$ of the bids were too high and $22 \%$ of the bids were too low. Five subjects out of 45 followed the value bidding strategy in all 10 auction periods. The average number of periods where a subject bid his value was 3.6 periods.

English auction: In the implemented version of the English auction the truth-telling strategy is to drop out as soon as the price $p$ exceeds the private valuation $v_{i}$, i.e. if $p=v_{i}+1$. Thus we consider it a value bid if the drop-out price was in the set $\left\{v_{i}, v_{i}+1, v_{i}+2\right\}$. If a player dropped out at a price below or above this set, we considered it as under- and overbidding, respectively. Normally one particular player, the winner of the auction, does not drop out and therefore does not completely reveal his bidding strategy. These cases we regarded as value bids as long as the elicited behavior was consistent with value bidding. ${ }^{7}$

Among 450 bids in the EA treatment $75 \%$ were value bids, $16 \%$ subjects were underbids and $9 \%$ overbids. If we neglect the observations from the auction winners (because their willingness to bid was not fully revealed), we observe a higher frequency of non-value bids (i.e. $63 \%$ value bids, $24 \%$ underbids and $13 \%$ overbids). Nine subjects (or $20 \%$ of all subjects) are consistent with value bidding in all 10 auction periods. The average number of periods where a subject bid his value was 7.4 periods.

Bisection auction: The bisection auction was implemented along the description in Section 2. Each period consisted of 7 rounds. In each round active bidders have to submit either yes or no for a current

\footnotetext{
${ }^{7}$ This classification can be viewed as too optimistic, i.e. we assume that buyers with a private value above the auction price would never overbid. However, we will also report data without taking these buyers into account.
} 
Table 1: Value bids across different treatments.

\begin{tabular}{lccc}
\hline & VA & EA & BA \\
\hline all observations & 450 & 450 & 450 \\
value bids & $48 \%$ & $75 \%$ & $72 \%$ \\
underbids & $22 \%$ & $16 \%$ & $14 \%$ \\
overbids & $30 \%$ & $9 \%$ & $14 \%$ \\
\hline fully informative observations & 450 & 305 & 164 \\
value bids & $48 \%$ & $63 \%$ & $68 \%$ \\
underbids & $22 \%$ & $24 \%$ & $17 \%$ \\
overbids & $30 \%$ & $13 \%$ & $15 \%$ \\
\hline number of value bidders & 5 & 9 & 7 \\
average number of truth-telling periods per subject & 3.6 & 7.4 & 6.7 \\
\hline
\end{tabular}

asked price. The truth-telling strategy is to regard the private valuation as threshold value and to state yes if the asked price is less or equal to the threshold, and no otherwise. It is an inherent feature of the bisection auction that bidders thresholds are only partially revealed. Hence, we cannot analyze behavior precisely but we have to rely on bidder's observable actions. Thus, we consider a strategy as value-bidding if in all observed rounds the bidder's submissions are consistent with a threshold from the set $\left\{v_{i}-1, v_{i}, v_{i}+1\right\}$. If the latent threshold proved to be lower or higher than this set, then the bidding strategy was considered to be an under- or overbid, respectively. ${ }^{8,9}$

The analysis of the data gives us the following results: in $72 \%$ of all 450 cases subjects were consistent with value bidding, in 14\% they were underbidding and in $14 \%$ they overbid. If we restrict the analysis to those bidders who were active all 7 rounds of a period (i.e subjects whose strategy we could observe to the very end) the frequencies were almost the same: $68 \%$ value-bidding, $17 \%$ underbidding and $15 \%$ of overbidding. Seven subjects out of 45 (or 15\%) followed the value bidding strategy in all 10 auction periods. The average number of periods where a subject was consistent with value-bidding was 6.7 periods.

Table 1 gives an overview over the value bids across treatments. It seems evident that EA and BA outperform VA with respect to value bidding. In order to test this we calculated the average frequency of value bidding per session and treatment, using all observations as well as using only the fully informative observations (i.e bids where we could observe the strategy to the very end). A nonparametric MannWhitney-U test on the session level yields a significant difference between BA and VA as well as between

\footnotetext{
${ }^{8}$ As for the English auction this classification can be seen as too optimistic. Hence we also report data from those bidders who stayed active till the end of the auction (at least one bidder per auction).

${ }^{9}$ Notice that in a period a player can't overbid in one round and underbid in another. Indeed if in a round a player overbids and stays active, then in the next rounds the ask prices are certainly above his valuation so that underbidding is not possible anymore. Similar, if in a round a player underbids and stays active, then in the next rounds the ask prices are certainly below his valuation so that overbidding is not possible anymore.
} 

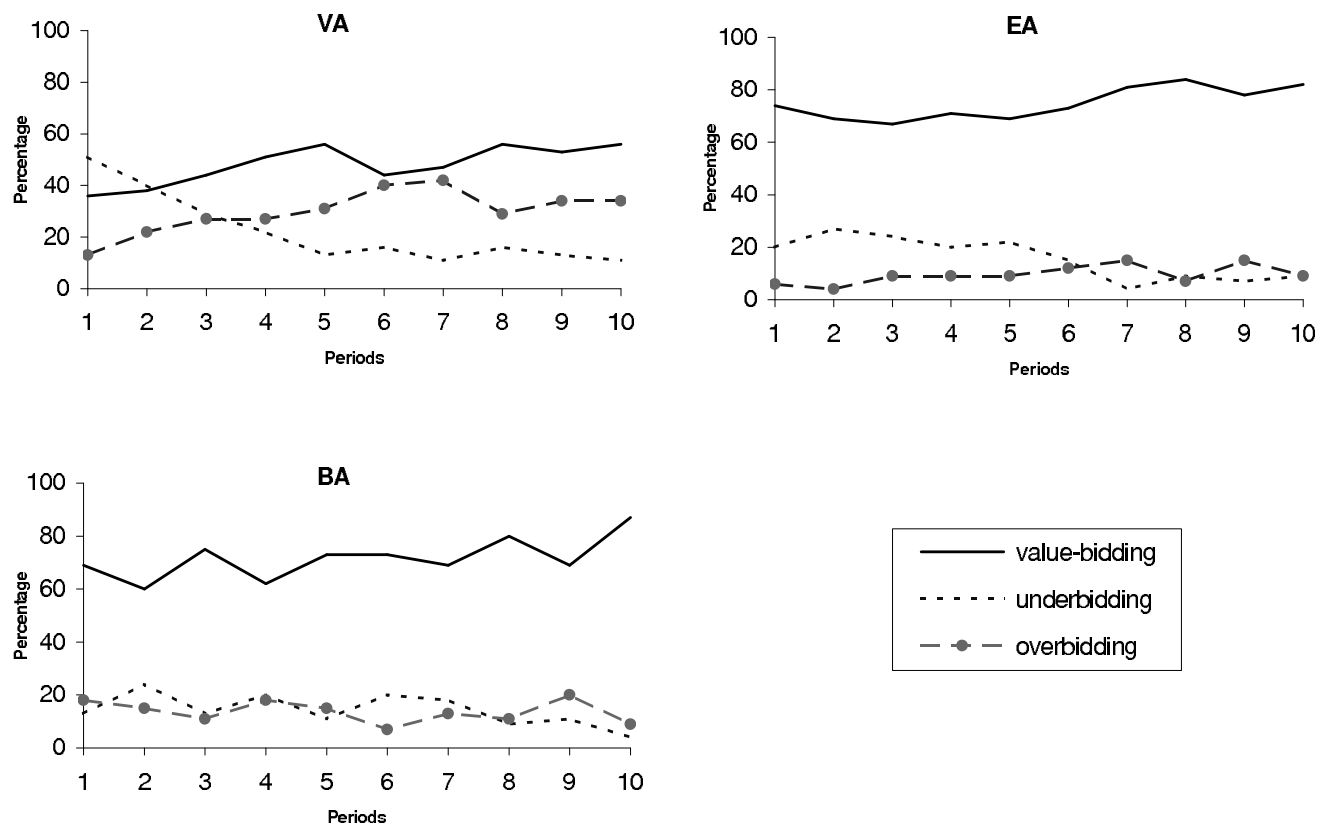

Figure 1: Bidding behavior: frequency of the different types of bids.

EA and VA. In both cases the null hypothesis that the frequency of value bidding is equal was rejected in favor of statement that frequency is smaller in VA treatment (Mann-Whitney-U test, $N=10$ for each comparison, one-sided; based on all observations: $p=0.004$ for both comparisons; based on the fully informative observations: $p=0.079$ for comparison VA with BA and $p=0.0159$ for comparison VA with EA). Between treatments BA and EA we did not find any significant difference. We summarize this in

Result 1 In terms of value bidding the bisection auction is comparable to the English auction and significantly better than the Vickrey auction.

\subsection{Learning process}

In section 4.1 we analyzed the different auction formats from a static viewpoint. However for the question of practical usability of the bisection auction it is also important to take a dynamic viewpoint. Do subjects learn to place value bids? To answer this we analyze whether subjects get closer to value-bidding as they gained more experience. For a first glance, Figure 1 shows how the frequencies of value-bidding, underand over-bidding develop over time. 
For each of the treatments, there is a tendency that value-bidding increases over time and underbidding decreases over time. For VA these tendencies are most pronounced. With respect to overbids only VA shows a clear tendency, with the other treatments it seems not to be clear. Interestingly, the number of overbids in VA tends to increase rather than to decrease. In order to test the results statistically we compare the number of deviations from value-bidding in the beginning of a session (periods 1-3) with the number of deviations at the end of a session (periods 8-10) for each subject. We assume one subject to be an independent observation and test the following null hypothesis: the number of deviations from value-bidding in periods $1-3$ is the same as in periods $8-10$. For each the treatments we can reject the null hypothesis in favor of the alternative hypothesis that the number of deviations in the beginning of a session is higher than at the end of a session (Wilcoxon signed-rank test, $N=45$ for each treatment, $p \leq 0.02$, one-sided).

The assumption of one subject being an independent observation is disputable. It rests on the fact that subjects were randomly matched to other subjects in each round. They neither learned to whom they were matched nor did they learn something about the other bidders values or bidding strategies. The only thing they got to know was the final price and whether they bought the object or not. ${ }^{10}$ Nevertheless, subjects interacted with each other repeatedly and their behavior is not strictly independent. Hence, we run the same test on the level of independent observations (session-level) and we get similar results, although only weakly significant (Wilcoxon signed-rank test, $N=5$ for each treatment, $p=0.0625$, one-sided).

The tests above only make use of the cases were indeed some differences were found in the behavior at the beginning and at the end (see e.g. [11]). This applies to 23, 29, and 26 subjects for the treatments VA, EA, and BA, respectively. Among those subjects who did not contribute to the test results we can distinguish between subjects who did not deviate from value bidding in any of the periods 1-3 and 8-10 and those subjects who did deviate to the same extend in the beginning and the end.

The first group of subjects always behaved rationally and therefore could not improve behavior. The numbers of subjects were 5, 12, and 15, for VA, EA, and BA, respectively. Apparently there is more rational behavior in EA and BA than in VA. In order to confirm this statistically we calculated the average number of rational subjects (who placed value bids from the beginning) for each session. We can reject the hypothesis of equal number of rational bidders in favor of the hypothesis that there are

\footnotetext{
${ }^{10}$ Some information could be extracted from the prices. For example since the VA price is the second highest bid, one could infer that at least one bidder must have bid this price. However this information is rather vague and moreover it does not give much information about the bidding strategy conditional on the valuation.
} 
Table 2: Learning across different treatments.

\begin{tabular}{lccc}
\hline & VA & EA & BA \\
\hline learning not to deviate & & & \\
subjects (WSR, one-sided) & $p=0.02$ & $p=0.02$ & $p=0.02$ \\
sessions (WSR, one-sided) & $p=0.0625$ & $p=0.0625$ & $p=0.0625$ \\
\hline learning not to severely deviate & & & \\
subjects (WSR, one-sided) & $p=0.0013$ & n.s. & $p=0.0013$ \\
sessions (WSR, one-sided) & $p=0.0313$ & n.s. & $p=0.0313$ \\
\hline \# rational bidders in periods 1-3 and 8-10 & 5 & 12 & 15 \\
\# non-learners in periods 1-3 and 8-10 & 17 & 5 & 4 \\
\# non-learners of severe deviations & 7 & 4 & 1 \\
\hline
\end{tabular}

more rational bidders in EA and BA than in VA (Mann-Whitney-U test, $N=10$ for each comparison, $p \leq 0.03$, one-sided). A comparison between EA and BA does not result in significant differences.

The second group of subjects did not behave rationally and did also not learn to do so. The numbers of subjects are 17, 5, and 4, for VA, EA, and BA, respectively. Apparently the number of non-learners is much higher in VA than in the other auctions. In the same manner as above we can reject the hypothesis that the number of non-learners is equal between VA and each of the other auctions in favor of the hypothesis that the number of non-learners is higher in VA (Mann-Whitney-U test, $N=10$ for each comparison, $p<0.01$, one-sided).

Table 2 gives an overview over the results. The whole analysis of this section was also done with respect to severe deviations. We considered a deviation as severe if the bid / drop-out price / threshold value had a difference of more than 5 to the dominant value. ${ }^{11}$ The learning results were slightly stronger for severe deviations in VA and BA. For EA no significance was found due to the scarcity of severe deviations.

In context of learning it is interesting to mention the observation made for the Vickrey auction. We observed that in VA out of 67 cases where a bidder overbid and won ${ }^{12}$, only 15 (22\%) led to a loss for the bidder. Only in 3 out of the 15 cases a bidder revised his behavior after suffering a loss. Moreover, there were 3 bidders who had losses more than once. This illustrates quite well that even from earlier encountered losses bidders hardly learned that overbidding in the Vickrey auction is dominated. This

\footnotetext{
${ }^{11}$ The precise definition of severe deviation for BA treatment would be: If in at least one round of a period an ask price is more than 5 above the bidder's private valuation and he submits yes then the bidder is considered to severely overbid. If in at least on round of a period an ask price is more than 5 below the bidder's private valuation and he submits no then the bidder is considered to severely underbid.

${ }^{12}$ Almost every second winner overbid his valuation.
} 
Table 3: Revenue across different treatments.

\begin{tabular}{lccc}
\hline & VA & EA & BA \\
\hline average revenue in ECU & 64.14 & 64.42 & 63.88 \\
\% of auction with pred. rev. level & $42 \%$ & $60 \%$ & $52 \%$ \\
avg. abs. diff. between result and pred. in ECU & 5.58 & 2.82 & 4.39 \\
\hline
\end{tabular}

observation goes along with a result of Kagel [8] who found that the feedback mechanism to learn and correct overbidding is weak in the Vickrey auction. To compare it with BA: out of 29 cases where the winner overbid (which is half as much as in VA) the winner lost money in 13 cases (45\%). After suffering from losses only in 4 cases subjects continued overbidding.

Summarizing the findings we get

Result 2 In all treatments subjects learn to adjust their behavior in the direction of the dominant strategy. However, in EA and BA there are significantly more subjects bidding rational right from the beginning and significantly less subjects who do not adjust their behavior.

\subsection{Revenue}

According to the theoretical prediction the equilibrium price of an auction, and consequently revenue for the auctioneer must be identical across treatments. Moreover the revenue should be equal to the second highest valuation among the bidders of an auction. To compare the revenues we take a look at the following measurements: first, we are interested in the average resulting revenue; second, the percentage of auctions with the resulting revenue at the predicted level; ${ }^{13}$ and third, the average absolute difference between the resulting and the predicted revenue. Table 3 presents the results aggregated over all sessions and periods. We see that the English auction performs "best" in all three measures. With the exception of average revenue the bisection auction comes second while the Vickrey auction comes last.

Testing the results of average revenue on a session level yields no significance. There is, however, a difference in the percentage of auctions with the predicted revenue level between VA and EA as well as between VA and BA. In both cases the null hypothesis of equal percentages is rejected in favor of the alternative hypothesis that the percentage is smaller in VA (Mann-Whitney-U test, $N=10$ for each comparison, $p<0.05$, one-sided). However, we are unable to reject, at conventional significance level,

\footnotetext{
${ }^{13}$ Similar as with the definition of a value bid, we accept a deviation by 1 ECU from the predicted revenue.
} 
the hypothesis of equality of the percentages for EA and BA. We did not find any significant difference when comparing the percentages of auctions with a revenue higher than the predicted level. Neither did we find any significant difference for the percentages of auctions with a revenue smaller than the predicted level.

Further, the tests show that the average absolute difference between the resulting and the predicted revenue is not the same for EA and BA as well as for EA and VA. In both cases the null hypothesis is rejected in favor of the alternative hypothesis which states that this difference is smaller in EA (MannWhitney-U test, $N=10$ for each comparison, $p<0.05$, one-sided). A comparison of VA and BA does not result in significant differences.

Summarizing this section we achieve:

Result 3 Prices and therefore revenues are significantly more accurate in the English auction than in the other two auction formats. Between the accuracy of the other formats, there is no significant difference. The average revenues do not significantly differ from each other.

\subsection{Efficiency}

An efficient allocation requires assigning an object to the bidder with the highest valuation, because independent of the price this maximizes total social welfare. We compare the auction formats with respect to three different efficiency measures: allocative efficiency, absolute loss of efficiency and relative loss of efficiency. The term allocative efficiency refers simply to the percentage of efficiently allocated objects (i.e. the bidder with the highest valuation has to receive the object). Measuring efficiency in this way does not however reflect the actual magnitude of efficiency lost due to misallocations. If the "wrong" bidder obtains an object, his valuation may be substantially or only slightly below the highest bidder's valuation, causing either dramatic or small welfare losses. Our second and third measures take this into account. With absolute loss of efficiency we refer to the difference between maximum possible welfare and achieved welfare, i.e the difference between the bidders' highest valuation and the valuation of the bidder who wins the auction. The relative loss of efficiency measures the loss of efficiency relative to the maximum possible welfare.

For each measure described above we calculated aggregate results over all sessions and periods (see Table 4). Again treatment EA shows the best figures. It is followed by VA and then by BA. However, there is 
Table 4: Efficiency across different treatments.

\begin{tabular}{lccc}
\hline & VA & EA & BA \\
\hline allocative efficiency & $86 \%$ & $92 \%$ & $86 \%$ \\
absolute efficiency loss in ECU & 1.22 & 0.63 & 1.59 \\
relative efficiency loss & $1.59 \%$ & $0.83 \%$ & $2.03 \%$ \\
\hline
\end{tabular}

only one result which is significant: the hypothesis that EA and BA yield the same relative efficiency loss can be rejected in favor of the hypothesis that EA yields a lower relative efficiency loss (Mann-Whitney-U test, $N=10, p=0.047$, one-sided). While it seems that VA outperforms BA, the results are in favor of $\mathrm{BA}$ if we only take the last 3 periods into account: the figures for $\mathrm{VA}$ are $82.2 \%, 0.95,1.31 \%$; for $\mathrm{BA}$ they are $88.9 \%, 0.77,1.02 \%$. None of the measures differs significantly, however.

To sum up:

Result 4 No strong conclusive result can be found with respect to efficiency.

\subsection{Post-experimental questionnaire}

Since theory does not predict any significant differences in behavior but differences can be found it makes sense to simply ask subjects about their strategies and thoughts. This was done in a post-experimental questionnaire. ${ }^{14}$ Two problems occur with such kind of data. First the answers were not paid and hence subjects could write anything they want. Second, most questions asked for free text answers and hence it is difficult to provide quantitative summaries. Nevertheless we make the attempt to report a selection of the data. Both authors have investigated the questionnaires independently, classifying the answers into different types. Then we merged our classifications and the corresponding data to the following summary. ${ }^{15}$

Vickrey auction. Twenty two out of 45 subjects indicated that they have chosen (not always from the beginning of the session) the private valuation as a bid. Seven subjects wrote that they have explicitly decided to make bids below their private valuation. Sixteen subjects indicated overbidding as a strategy they have chosen to follow. Half of those 16 bid above their private value only if this value was very high. From the answers of the overbidders we could see that many of them (namely 13) disconnected

\footnotetext{
${ }^{14}$ The questionnaire can be found in the Appendix 2.

${ }^{15}$ The raw data is available from the authors on request.
} 
the probability of getting the object from the price paid. By bidding higher than the private value they thought to increase the probability without influencing the price they had to pay in case they win. They failed to see that it were only the bad cases they won additionally.

English auction. The majority of the subjects, namely 34 out of 45 , indicated that they dropped out of the auction as soon as the price reached (or just past) their valuation. Underbidding and overbidding were mentioned as a chosen strategy by 3 and 7 subjects, respectively. The underbidders attempted to collude. When having a low private value they explicitly dropped out quickly after the period began in order to decrease the price and therefore to increase the profit of the winner. Contrary, 3 of the 7 overbidders exhibited competitive behavior. They stayed active longer in order to increase the price and thus to decrease the profit of the winner, hoping not to become the winner themselves.

Bisection auction. The most frequently mentioned strategies in BA were: submit "No" if the asked price is greater than the private value (21 subjects); and submit "Yes" if the current price is smaller than the private value (25 out of 45 subjects). ${ }^{16}$ Eight subjects mentioned that they chose to underbid while 9 mentioned overbidding. Seven subjects mentioned that sometimes, regardless of the private value, they submitted "No" in order to make the price to go down, hoping to increase thereby their potential profit. Four subjects indicated that regardless of their valuation they submitted "Yes" in the first round in order not to be dropped out from the auction immediately. Also with the two last types we see that 13 subjects disconnected the price from the probability to win. They either tried to increase the probability without taking into account the price. Or they tried to lower the price without realizing (or at least underestimating) the risk to be dropped out.

Over all treatments several subjects wrote that the more money they obtained the more risk they were willing to take. Many also explicitly mentioned the avoidance of losses as a primary goal. This was mentioned by 11,8 and 5 subjects in VA, BA and EA, respectively.

One of our goals was explicitly to test the auction mechanisms among non-professional bidders. However an explicit restriction of the recruitment to subjects without auction knowledge had probably attracted even more experienced subjects, since they might have thought to make a lot of money easily. Consequently we asked subjects about their pre-knowledge ex-post. The answers are summarized in Tables 5 and $6 .{ }^{17}$ By and large the pre-knowledge seems to be rather similar across treatments with the exception of the experience of online auctions in EA. However, most important for our purpose is that subjects in

\footnotetext{
${ }^{16}$ Some mentioned both and hence the total number sums up to more than 45 .

${ }^{17}$ The questions about theoretical knowledge and practical experience were only asked in sessions $3-5$ of the treatments, so the table contains data on percentage of responded subjects.
} 
Table 5: Questionnaire: subjects' knowledge of auction theory.

\begin{tabular}{lccc}
\hline auction theory & VA & EA & BA \\
\hline knowledge & & & \\
thorough & $10 \%$ & $10 \%$ & $7 \%$ \\
superficial & $26 \%$ & $27 \%$ & $21 \%$ \\
no & $64 \%$ & $63 \%$ & $72 \%$ \\
\hline
\end{tabular}

Table 6: Questionnaire: practical experience of the subjects.

\begin{tabular}{lccc}
\hline online auctions & VA & EA & BA \\
\hline experience & & & \\
frequently & $0 \%$ & $22 \%$ & $0 \%$ \\
sometimes & $30 \%$ & $41 \%$ & $18 \%$ \\
never & $70 \%$ & $37 \%$ & $82 \%$ \\
\hline
\end{tabular}

\begin{tabular}{lccc}
\hline other auctions & VA & EA & BA \\
\hline experience & & & \\
frequently & $0 \%$ & $0 \%$ & $0 \%$ \\
sometimes & $7 \%$ & $8 \%$ & $18 \%$ \\
never & $93 \%$ & $92 \%$ & $82 \%$ \\
\hline
\end{tabular}

treatment BA did not have more pre-knowledge then in the other auction formats.

Finally we asked subjects what they consider to be the optimal strategy. Subjects were given a predetermined set of answers which differ only in their degree of deviation from the dominant strategy. Depending on the treatment the answer implied a bid (VA), a drop-out price (EA), or threshold value (BA). The potential answers we gave to the subjects and the data are shown in Table $7 .{ }^{18}$

It can be seen that EA subjects produced the most correct answers, closely followed by the VA subjects. The BA subjects gave the correct answer only in $22 \%$ of the cases and therefore differ significantly from the other two treatments (Fisher exact test, $N=90$ for both comparisons, $p<0.001$, two-sided). ${ }^{19}$

It is interesting to compare the answers of the questionnaire with the decisions actually made in the auctions. We say that a subject behaved consistently in a period if her decision in this period was in the same category as the answer. Taking a look at the last three periods we found that in VA 22 subjects (49\%) were consistent in their decisions with what they considered to be optimal. Regarding the last two periods both decisions were in the same category as the answer for 24 subjects (53\%). Investigating the very last period we see 30 subjects $(67 \%)$ to be consistent. The results in EA turned out to be almost the same, namely 21 (47\%), $22(49 \%)$ and 30 (67\%), respectively.

It is quite difficult to check consistency of subjects in BA, because it is rarely possible to find a unique

\footnotetext{
${ }^{18}$ The question for the English auction was framed in such a way that also "exactly equal to the private value" was the right answer.

${ }^{19}$ We neglect any dependence of persons here.
} 
Table 7: Questionnaire: choice of the optimal strategy.

\begin{tabular}{lccc}
\hline & VA & EA & BA \\
\hline a number that is & & & \\
5 or more below the private value & 2 & 0 & 18 \\
less than 5 below the private value & 4 & 6 & 9 \\
exactly equal to the private value & 25 & 27 & 10 \\
less than 5 above the private value & 8 & 10 & 4 \\
5 or more above the private value & 6 & 2 & 4 \\
\hline
\end{tabular}

threshold that corresponds to the used strategy. Only for a player who is active during all 7 rounds of an auction the threshold can be find precisely, but if a player drops out or becomes the winner earlier then we can only define a set of thresholds that correspond to actions he made. Since thresholds from this set can be in different categories relatively to the player's valuation we cannot say for sure whether he is consistent or not. ${ }^{20}$ However, it is interesting to notice that among 25 subjects who behaved optimally in more than 6 periods only 9 have answered the question correctly. Fifteen subjects decided that the optimal threshold is below the valuation and 1 subject above the valuation. Among these 16 subjects 13 indicated that making decisions they often or even always thought in terms of threshold strategy.

Taking together the answers in the post-experimental questionnaire we find the following

Result 5 Despite the fact that the questionnaire was not paid according to performance we have no reason to doubt that subjects answered truthfully. The answers give us the following insights:

1. Pre-knowledge of subjects was quite comparable except in the experience with online auctions. There, however, VA and BA subjects had less experience than EA subjects and therefore our positive findings with respect to $V A$ and $B A$ are conservative.

2. In EA, deviations from the truth-telling strategy were mainly driven by social preferences. Cognitive issues seem to be a minor problem. In VA and BA several persons get trapped by the thoughts that it is possible to regard the probability to win and the expected price as independent items to optimize. They thought they could change one item with holding the other constant. This view can cause overbidding as well as underbidding.

3. In $B A$ it seems to be least clear what the optimal strategy is.

\footnotetext{
${ }^{20}$ For instance, in the example from Section 2 actions of player B could correspond to a threshold strategy with any threshold from set $[0,7]$. Notice that some thresholds from this set are less than valuation of player B and some are greater.
} 


\section{Summary and Conclusions}

The bisection auction is strategically equivalent to the Vickrey and the English auction. However, previous results from the comparison of the Vickrey and the English auction have shown that we should be cautious when drawing conclusions for the behavioral equivalence. Given that the bisection auction does offer some advantages over the others in terms of speed and information revelation, the question rises whether it could be used in practical settings as well. An ultimate answer to this can of course only be given after a real practical application. The experiment can be seen as a first step into this direction.

In the paper we compared the bisection mechanism to two other mechanisms, the Vickrey auction and the English auction. By and large the bisection auction performs somewhere in-between the others. It is significantly better than the Vickrey auction (i.e. closer to theoretical predictions) with respect to the frequency of value-bidding and the accuracy of the price. Compared to the English auction it performs worse with respect to severe deviations from value bidding, the relative loss in efficiency and the absolute difference between resulting and predicted revenue (see Tables 8 and 9 for the summary of the results).

A major reason for subjects to deviate from value bidding seems to be the thought that probability to win can be seen independently from the expected price. Subjects who overbid in the Vickrey auction, for example, increase the probability to win but they fail to see that the additional cases are those that give a negative payoff. Some of the subjects see this negative dependence but they underestimate the consequences. ${ }^{21}$ Similar thoughts are possible for the bisection auction: As laid out in Section 4.5, some subjects submitted always "Yes" or "No" in the first round in order to increase the probability to win or to decrease the expected price, respectively.

Given that the bisection auction faces the same cognitive trap as the Vickrey auction it is interesting to see that fewer people run into it. We speculate that the reason therefore is that the bisection auction is much more complex than the Vickrey auction. This has been evidenced by the huge number of wrong answers in the questionnaire. People bidding their value know that they will not lose. The more complex design of BA makes them more careful with respect to deviations. This is different in VA where some very simple rules give subjects the impression to overview the situation.

There is one issue about the practical application that is still open and subject to further research. In the Vickrey and the English auction the price and the winner are determined at the same time. In the bisection auction normally the winner is determined first, then the auction goes on with the

\footnotetext{
${ }^{21}$ For a rational person no estimate is necessary. Overbidding is dominated. People who are, however, not able to analytically understand the Vickrey auction might well just estimate an influence on the expected price.
} 
Table 8: Comparison of treatments.

\section{BA vs. VA BA vs. EA EA vs. VA}

\section{Bidding behavoir}

frequency of value-bidding
$\mathrm{BA} \succ_{0.01} \mathrm{VA}$
$\mathrm{BA} \approx \mathrm{EA}$
$\mathrm{EA} \succ_{0.01} \mathrm{VA}$
$\mathrm{BA} \succ_{0.01} \mathrm{VA} \quad \mathrm{BA} \approx \mathrm{EA}$
$\mathrm{EA} \succ_{0.02} \mathrm{VA}$

fully informative observations

number of rational bidders

in periods $1-3$ and $8-10$
all deviations
$\mathrm{BA} \succ_{0.05} \mathrm{VA}$
$\mathrm{BA} \approx \mathrm{EA}$
$\mathrm{EA} \succ_{0.05} \mathrm{VA}$
severe deviations
$\mathrm{BA} \succ_{0.05} \mathrm{VA} \quad \mathrm{EA} \succ_{0.05} \mathrm{BA}$
$\mathrm{EA} \succ_{0.01} \mathrm{VA}$

number of non-learners

in periods $1-3$ and $8-10$
all deviations
$\mathrm{BA} \succ_{0.01} \mathrm{VA}$
$\mathrm{BA} \approx \mathrm{EA}$
$\mathrm{EA} \succ_{0.01} \mathrm{VA}$
severe deviations
$\mathrm{BA} \approx \mathrm{VA}$
$\mathrm{EA} \approx \mathrm{BA}$
$\mathrm{EA} \approx \mathrm{VA}$

\section{Efficiency}

$\%$ of auctions with

efficient allocation

absolute loss of efficiency

$\mathrm{BA} \approx \mathrm{VA}$

$\mathrm{BA} \approx \mathrm{EA}$

$\mathrm{EA} \approx \mathrm{VA}$

relative loss of efficiency

$\mathrm{BA} \approx \mathrm{VA}$

$\mathrm{BA} \approx \mathrm{EA}$

$\mathrm{EA} \approx \mathrm{VA}$

$\mathrm{BA} \approx \mathrm{VA}$

$\mathrm{EA} \succ_{0.05} \mathrm{BA}$

$\mathrm{EA} \approx \mathrm{VA}$

\section{Revenue}

revenue

$\mathrm{BA} \approx \mathrm{VA}$

$\mathrm{BA} \approx \mathrm{EA}$

$\mathrm{EA} \approx \mathrm{VA}$

$\%$ of auctions with revenue at the predicted level

$\mathrm{BA} \succ_{0.05} \mathrm{VA} \quad \mathrm{BA} \approx \mathrm{EA} \quad \mathrm{EA} \succ_{0.05} \mathrm{VA}$

absolute difference between resulting and predicted revenue

$\mathrm{BA} \approx \mathrm{VA}$

$\mathrm{EA} \succ_{0.05} \mathrm{BA}$

$\mathrm{EA} \succ_{0.05} \mathrm{VA}$

Note: $\mathrm{BA} \succ_{0.05} \mathrm{VA}$ means that the bisection auction outperforms the Vickrey auction (in terms of a particular measurement) at the level of significance 0.05 . EA $\approx \mathrm{BA}$ means that there is no significant (any level less than 0.1) difference between the performance (in terms of a particular measurement) of the English and the bisection auctions. 
Table 9: Comparison of measurements of a particular treatment over time.

\begin{tabular}{llll}
\hline BA & EA & VA \\
\hline \hline
\end{tabular}

\section{Bidding behavior}

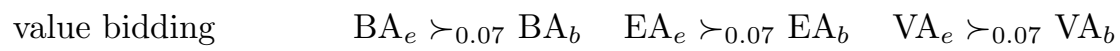

\section{Learning process}

$\begin{array}{lllllll}\text { all deviations } & \mathrm{BA}_{e} \succ_{0.05} & \mathrm{BA}_{b} & \mathrm{EA}_{e} \succ_{0.05} & \mathrm{EA}_{b} & \mathrm{VA}_{e} \succ_{0.05} \mathrm{VA}_{b} \\ \text { severe deviations } & \mathrm{BA}_{e} \succ_{0.01} & \mathrm{BA}_{b} & \mathrm{EA}_{b} \approx \mathrm{EA}_{e} & \mathrm{VA}_{e} \succ_{0.01} \mathrm{VA}_{b}\end{array}$

Note: $\mathrm{BA}_{e} \succ_{0.05} \mathrm{BA}_{b}$ means that the performance of the bisection auction (in terms of a particular measurement) is improved (at the level of significance 0.05) at the end in comparison with the beginning. $\mathrm{EA}_{b} \approx \mathrm{EA}_{e}$ means that there is no significant (any level less than 0.1) difference between the performance of the English auction (in terms of a particular measurement) in the beginning and at the end. N.e.d. means that there is not enough informative data to make any conclusion.

determination of the price. Moreover the winner can conclude from the price movements that she has been determined the winner (i.e. she submitted "yes" and nevertheless the asked price drops). In theory as well as in the laboratory there is no communication between the winner and the other bidders. Hence the problem does not exist there, since no bidder except the winner does know that the object is already gone. However, in practical settings the winner might communicate his win and other bidders might drop out of the auction. This could lead to an interesting instance of cartel behavior. On the other hand the remaining bidders might engage in the spiteful action to drive up the price in order to harm the winner. This behavior would have the effect that the bisection auction remains efficient and gives a higher revenue to the auctioneer. Since we have seen some instances of competitive behavior in the EA treatment we may also expect it in real life settings. Eventually this issue is highly speculative and depends on the precise frame the auction takes place in. If the group of bidders knows each other, then the cartel appears to us as the natural consequence. However in competitive market settings where players get for example a long term advantage from driving out competitors from the market, they might try to harm others as severe as possible.

All in all it seems to us that it is worthwhile trying to implement the bisection auction in a real life setting. 


\section{References}

[1] Coppinger, V.M., Smith, V.L. and Titus, J.A. [1980] Incentives and behavior in English, Dutch and seled-bid auctions. Economic Inquiry, 43, pp. 1-22.

[2] David, E., Rogers, A., Schiff, J., Kraus, S. and Jennings, N.R. [2005] Optimal Design Of English Auctions With Discrete Bid Levels. In Proceedings of ACM Conference on Electronic Commerce (EC'05), Vancouver, Canada, pp. 98-107.

[3] Fischbacher, U. [1999] Z-Tree: Zurich Toolbox for Redymade Economic Experiments. Working paper No 21, Institute for Empirical Research in Economics, University of Zurich.

[4] Green, J. and Laffont, J-J. [1977] Characterization of satisfactory mechanisms for the revelation of preferences for public goods. Econometrica, 45, 427-438.

[5] Grigorieva, E., Herings, P.J-J., Muller, R. and Vermeulen, D. [2002] The private value single item bisection auction. Research Memorandum 51, METEOR, Maastricht University. To apper in Economic Theory.

[6] Harstad, R.M. [2000] Dominant strategy adoption and bidder's experience with pricing rules. Experimental Economics, 3, pp. 261-280.

[7] Kagel, J.H., Harstad, R.M. and Levin, D. [1987] Information impact and allocation rules in auctions with affiliated values: A laboratory study. Econometrica, vol.55, No.6, pp. 1275-1304.

[8] Kagel, J.H. and Levin, D. [1993] Independent private value auctions: bidder behaviour in first-, second- and third-price auctions with varying numbers of bidders. The Economic Journal, 103, pp. 868-879.

[9] Kagel, J.H. [1995] Auctions: A survey of experimental research. In The handbook of experimental economics, J.H.Kagel and A.E.Roth, eds., New Jersey: Princeton University Press.

[10] Rothkopf, M.H., Tisberg, T.J. and Kahn, E.P. [1990] Why are Vickrey auctions rare? Journal of Political Economy, 98, 94-109.

[11] Siegel, S. and Castellan, N.J. [1988] Nonparametric statistics for the behavioral sciences. McGrawHill Book Company.

[12] Vickrey, W. [1961] Counterspeculation, auctions and competitive sealed tenders. Journal of Finance, 16 , pp. $8-37$. 


\section{Appendix 1: Subjects instructions}

Dear participant, thank you for taking part in this experiment! It will last about 1 hour. You will be compensated according to your performance. In order to ensure that the experiment takes place in an optimal setting, we would like to ask you to follow the general rules during the whole experiment:

- Do not communicate with your fellow students!

- Please switch off your mobile phone!

- Please read the instructions carefully. It is important that you understand the rules of the experiment. If something is not explained well, please raise your hand. We will then answer your questions privately. The instructions are identical for all participants.

- You may make notes on this instruction sheet if you wish.

- After the experiment please remain seated till you are paid off.

- If you do not obey the rules, the data becomes useless for us. Therefore we will have to exclude you from this experiment and you will not receive any compensation.

Your decisions are anonymous. Neither your fellow students nor anybody else will ever learn them from us.

The experiment consists of 10 periods. In each period the participants are randomly matched into groups of three bidders. In each group a fictitious commodity is auctioned off. Before the auction starts you will receive information about your private value for the commodity, expressed in Experimental Currency Unit (ECU). The private values are independently and randomly determined. Thus, they may be different for different bidders. Each integer value between 32 and 95 is equally likely. If you win the auction you don't receive the commodity but you receive an amount of money equal to your private value. In return you have to pay the price resulting from the auction.

Who wins the auction and what price the winner has to pay is determined in the following way:

This part of the instructions is different for each treatment. See below the corresponding parts.

ECUs are transformed into Euros according to the following conversion rate: 1 Euro $=4.5 \mathrm{ECU}$. You will obtain an initial endowment of 3 Euro. If you make losses in an auction these will be 
deducted from your previous gains (or from your initial endowment). You will receive your final profit in cash at the end of the experiment.

Before the experiment starts please answer the following questions:

1. Assume three bidders Ann, Bert and Chris take part in the experiment. Ann gets informed about her private value which is 62 . What does Ann know about the private values of Bert and Chris?

(a) Bert and Chris have exactly the same private values, i.e. 62 .

(b) Bert and Chris have different private values, i.e. their values are between 32 and 95 but not 62.

(c) Bert and Chris may have the same but may also have different values, i.e their values are between 32 and 95 including 62 .

2. Assume that the participants have the following private values: Ann 57, Bert 41 and Chris 75 . Assume further that Ann wins the auction and that the price is 48 .

What are the profits of the three participants?

Ann:

Bert:

Chris:

3. Assume that the participants have the following private values: Ann 39, Bert 77 and Chris 77 . Assume further that Bert wins the auction and that the price is 83 .

What are the profits of the three participants?

Ann:

Bert:

Chris:

After the experiment, we would like to ask you to complete a short questionnaire.

Thank you again and good luck with the experiment! 


\section{Part of the instructions corresponding to the Vickrey auction.}

After you observe your private value, you have to place a bid which is allowed to be between 0 and 127 ECU. After every bidder in your group has placed his bid the winner and the price at which he obtains the commodity is determined. The bidder with the highest bid is the winner. The price he has to pay is equal to the second highest bid. If more than 1 bidder submitted the same highest bid, the winner is determined randomly among these bidders. The price he has to pay is, again, equal to the second highest bid which in this case coincides with the highest bid.

The profit of the winner is determined as the difference between his private value and the price. If his private value is greater than the price, he receives this difference. If his value is less than the price, he has to pay this difference. The other bidders do not receive anything and do not pay anything.

Please make your decisions carefully - your reward will depend on your performance during the experiment. Note that you can make losses, but it is always possible, however, to bid in such a way that you avoid losses for sure.

You will get information and make your decisions via the computer terminal. In each period you go through the following rounds:

- You observe your private value for the commodity. You will not be informed about the values of the others, just as they do not know your private value.

- You submit your bid which is allowed to be between 0 and 127 ECU.

- You observe whether or not you bought the commodity, the price, your gains/losses in this auction and in total including all previous auctions.

- A new period starts. You will be randomly matched to two other participants. 


\section{Part of the instructions corresponding to the English auction.}

The auction starts with a price of 0 . Every 2 seconds the current price is increased by 1 . As long as you are not reacting we assume that you are active, that means you are bidding the current price. If the price reaches a level which you are not willing to bid anymore you have to click the button "DROP OUT". From this moment on you are not active anymore. For active bidders the price continues to increase. The auction stops as soon as there is only one active bidder left. The last remaining bidder becomes the winner. The price the winner has to pay is 1 ECU below the price where the second last bidder dropped out. If several bidders drop out simultaneously and no bidder is left active, the winner is determined randomly among these bidders and the price is 1 ECU below the price where they dropped out. If upon reaching the maximal price of $128 \mathrm{ECU}$ there is more than one active bidder, then the commodity is randomly allocated among these active bidders for a price of 127 ECU.

The profit of the winner is determined as the difference between his private value and the price. If his private value is greater than the price, he receives this difference. If his value is less than the price, he has to pay this difference. The other bidders do not receive anything and do not pay anything.

Please make your decisions carefully - your reward will depend on your performance during the experiment. Note that you can make losses, but it is always possible, however, to bid in such a way that you avoid losses for sure.

You will get information and make your decisions via the computer terminal. In each period you go through the following rounds:

- You observe your private value for the commodity. You will not be informed about the values of the others, just as they do not know your private value.

- You observe successive change of the price and indicate your dropping out by clicking the button "DROP OUT" at the price you are not willing to bid any more.

- After the period ends you observe whether or not you bought the commodity, the price, your gains/losses in this period and in total including all previous periods.

- A new period starts. You will be randomly matched to two other participants. 


\section{Part of the instructions corresponding to the bisection auction.}

One period consists of 7 rounds. For each round the interval where the bidders are competing for the commodity is determined. The asked price in a round is set to the middle of this interval. In the first round the interval is $[0,128)$ and the asked price is equal to 64 . All bidders receive the status "Active". Active bidders are asked whether they are willing to bid the current asked price for the commodity. A bidder replies "YES" to announce his willingness and "NO" to announce his unwillingness. After all bidders submit their decision, the interval and the asked price of the next round as well as the status of bidders are determined according to the following rule:

- In case 3 "yes"-bids are submitted: All three bidders are willing to bid the asked price for one available commodity. It means that at the asked price demand exceeds supply and therefore we can concentrate our search to the upper half of the previous interval. The price goes up to the middle of this new interval. It means that in round 2 the interval will be $[64,128)$ and the price 96. All active bidders remain active.

- In case 2 "yes"-bids and 1 "no"-bid are submitted: Two bidders are willing to bid the asked price for one available commodity. It means that at the asked price demand exceeds supply and therefore, again, we can concentrate our search to the upper half of the previous interval. The price goes up to the middle of this new interval. It means that in round 2 the interval will be $[64,128)$ and the price 96 . The bidders that are active in the next round are the ones that submitted "yes"-bids. The bidder with a "no"-bid drops out of the auction. His status remains "Dropped out" till the end of the period. He is not free anymore to choose between "yes" and "no". Since the prices in all next rounds will be greater than the price that this bidder declined when he became a drop out, his decisions in all forthcoming rounds are considered to be " $n o$ ".

- In case 1 "yes"-bid and 2 "no"-bids are submitted: There is only one bidder who is willing to bid the asked price. The bidder with a "yes"-bid becomes the winner of the auction. His status remains "The winner" till the end of the period. The bidders that are active in the next round are the ones that submitted "no"-bids. By their future bids the price the winner has to pay is determined. The new interval is set equal to the lower half of the previous interval. So the price goes down to the middle of this new interval. It means that in round 2 the interval will be $[0,64)$ and the price 32 . The winner is not free to choose between "yes" and "no". Since the prices in all next rounds will be lower than the price that this bidder agreed on when he became the winner, his decisions in all forthcoming rounds are considered to be "yes". 
- In case 3 "no"-bids are submitted: No bidder is willing to bid the asked price for the commodity. It means that at the asked price supply exceeds demand and therefore we can concentrate our search to the lower half of the previous interval. So the price, again, goes down to the middle of this new interval. It means that in round 2 the interval will be $[0,64)$ and the price 32 . All active bidders remain active.

The way to decide about the status of bidders, the change of interval and the price is the same in all rounds. Depending on submitted bids we subsequently restrict attention to either the lower half or to the upper half of the previous interval. The only information bidders get after each round is the new interval, the new price and own status. The bidders are not informed about the status of others, so during the period you don't get to know whether there are drop outs or the winner among the other bidders. Thus, an active bidder does not know whether he is competing for the commodity or he is determining the winner's price. After round 7 the new interval is determined. The price the winner has to pay is equal to the lower bound of this interval. If the winner was not found during 7 rounds (i.e. if in no round exactly one bidder submitted a "yes"-bid), the status of the bidders after the last round is determined and the commodity is randomly allocated to one of the remaining active bidders.

The profit of the winner is determined as the difference between his private value and the price. If his private value is greater than the price, he receives this difference. If his value is less than the price, he has to pay this difference. The other bidders do not receive anything and do not pay anything.

Please make your decisions carefully - your reward will depend on your performance during the experiment. Note that you can make losses, but it is always possible, however, to bid in such a way that you avoid losses for sure.

You will get information and make your decisions via the computer terminal. In each period you go through the following phases of the auction:

- You observe your private value for the commodity. You will not be informed about the values of the others, just as they do not know your private value.

- ROUND 1: You are "Active". You observe the initial interval [0,128) and the initial price 64. You have to indicate your decision "YES, I'm willing to bid this price for the commodity" or "NO, I'm not willing to bid this price for the commodity" by clicking the corresponding button.

- ROUNDS 2-7: You observe your current status that can be "Active", "Dropped out" or "The 
winner". You observe the current interval and the current price. If you are active you have to indicate your decision "YES" or "NO" for the current price. If you are a drop out or the winner you are not allowed to submit bids anymore.

- After round 7 the period ends and you observe whether or not you bought the commodity, the winning price, your gains/losses in this period and in total including all previous periods.

- A new period starts. You will be randomly matched to two other participants. 


\section{Appendix 2: Post-experimental questionnaire}

Subject ID (see the card you have drawn in the beginning):

Year of birth:

Gender:

Nationality:

Study:

In the following we are interested to learn how you reached your decision. Please answer the following questions as precisely as possible.

What factors did influence your decision? What information did you use?

Given the information and factors mentioned above, how did you make up your strategy?

Did you encounter problems in particular with the software? If yes, what problems?

Did you ever deal with auctions in one of your courses?

yes, thoroughly

yes, but superficially

never

Do or did you participate in online auctions (e.g. www.ebay.com)?

$\bigcirc$ frequently

sometimes

$\bigcirc$ never

Do or did you participate in other but online auctions?

$\bigcirc$ frequently

sometimes

never

This last part of the questionnaire is different for each treatment. See below the corresponding parts. 


\section{Part of the questionnaire corresponding to BA treatment.}

Consider the following strategy: Given your private value of the commodity you chose a number. Whenever the asked price is equal to or below this number you submit "Yes". If the asked price is above this number you submit "No".

Did you use such a threshold strategy?

$\bigcirc$ always

$\bigcirc$ often

sometimes

$\bigcirc$ never

Suppose you cannot participate in the auction yourself but you can submit a number to a software agent who bids for you according to the strategy described in the question above.

Given that you know your private value, which number would maximize your payoff?

$\bigcirc$ a number that is 5 or more below the private value

a number that is less than 5 below the private value

$\bigcirc$ the number exactly equal to the private value

$\bigcirc$ a number that is less than 5 above the private value

$\bigcirc$ a number that is 5 or more above the private value 


\section{Part of the questionnaire corresponding to VA treatment.}

Which strategy do you consider to maximize your payoff?

$\bigcirc$ submit a bid that is 5 or more below the private value

submit a bid that less than 5 below the private value

$\bigcirc$ submit a bid exactly equal to the private value

submit a bid that is less than 5 above the private value

$\bigcirc$ submit a bid that is 5 or more above the private value

\section{Part of the questionnaire corresponding to EA treatment.}

Which strategy do you consider to maximize your payoff?

$\bigcirc$ drop out if the price exceeds a value which is 5 or more below the private value

$\bigcirc$ drop out if the price exceeds a value which is less than 5 below the private value

$\bigcirc$ drop out if the price exceeds the private value

$\bigcirc$ drop out if the price exceeds a value which is less than 5 above the private value

$\bigcirc$ drop out if the price exceeds a value which is 5 or more above the private value 


\section{Appendix 3: Tables with data used for the conducted tests}

\begin{tabular}{lrrrrr}
\hline & session 1 & session 2 & session 3 & session 4 & session 5 \\
\hline \hline & & & & & \\
$\mathrm{BA}$ & $64.4 \%$ & $81.1 \%$ & $68.9 \%$ & $75.5 \%$ & $68.9 \%$ \\
$\mathrm{BA}_{b}$ & $48.1 \%$ & $85.2 \%$ & $74.1 \%$ & $70.4 \%$ & $59.2 \%$ \\
$\mathrm{BA}_{e}$ & $88.9 \%$ & $88.9 \%$ & $74.1 \%$ & $81.5 \%$ & $70.4 \%$ \\
\hline & & & & & \\
$\mathrm{VA}$ & $53.3 \%$ & $26.6 \%$ & $45.5 \%$ & $60.0 \%$ & $54.4 \%$ \\
$\mathrm{VA}_{b}$ & $33.3 \%$ & $25.9 \%$ & $25.9 \%$ & $59.2 \%$ & $51.8 \%$ \\
$\mathrm{VA}_{e}$ & $59.2 \%$ & $25.9 \%$ & $70.4 \%$ & $66.7 \%$ & $55.5 \%$ \\
\hline & & & & & \\
$\mathrm{EA}$ & $69.9 \%$ & $76.7 \%$ & $68.9 \%$ & $76.7 \%$ & $75.5 \%$ \\
$\mathrm{EA}_{b}$ & $62.9 \%$ & $77.8 \%$ & $62.9 \%$ & $70.4 \%$ & $59.2 \%$ \\
$\mathrm{EA}_{e}$ & $62.9 \%$ & $81.5 \%$ & $70.4 \%$ & $88.9 \%$ & $92.6 \%$ \\
\hline
\end{tabular}

Table 10: Frequency of value bidding.

session $1 \quad$ session $2 \quad$ session $3 \quad$ session $4 \quad$ session 5

\begin{tabular}{llllll}
\hline \hline & & & & & \\
BA & $65.7 \%$ & $66.6 \%$ & $63.5 \%$ & $71.9 \%$ & $58.9 \%$ \\
VA & $53.3 \%$ & $26.6 \%$ & $45.5 \%$ & $60.0 \%$ & $54.4 \%$ \\
EA & $71.0 \%$ & $65.6 \%$ & $53.4 \%$ & $67.7 \%$ & $63.3 \%$ \\
\hline
\end{tabular}

Table 11: Frequency of value-bidding among the players with fully informative bids.

\begin{tabular}{rrrrrr}
\hline & session 1 & session 2 & session 3 & session 4 & session 5 \\
\hline \hline & & & & & \\
BA & $21.1 \%$ & $12.2 \%$ & $15.6 \%$ & $3.3 \%$ & $20.0 \%$ \\
VA & $17.8 \%$ & $23.3 \%$ & $41.1 \%$ & $11.1 \%$ & $17.8 \%$ \\
EA & $7.8 \%$ & $15.5 \%$ & $18.9 \%$ & $18.9 \%$ & $23.3 \%$ \\
\hline
\end{tabular}

Table 12: Frequency of underbidding. 
session $1 \quad$ session $2 \quad$ session $3 \quad$ session $4 \quad$ session 5

\begin{tabular}{lrrrrr}
\hline \hline & & & & & \\
BA & $14.4 \%$ & $6.7 \%$ & $15.5 \%$ & $21.1 \%$ & $11.1 \%$ \\
VA & $28.9 \%$ & $50.0 \%$ & $13.3 \%$ & $28.9 \%$ & $27.7 \%$ \\
EA & $22.2 \%$ & $7.8 \%$ & $12.2 \%$ & $4.4 \%$ & $1.1 \%$ \\
\hline
\end{tabular}

Table 13: Frequency of overbidding.

session 1 session 2 session 3 session 4 session 5

\begin{tabular}{llllll}
\hline \hline all deviations & & & & & \\
BA & 1 & 5 & 4 & 3 & 2 \\
VA & 1 & 0 & 0 & 2 & 2 \\
EA & 2 & 3 & 3 & 1 & 3 \\
& & & & & \\
\hline & & & & & \\
severe deviations & 1 & 6 & 5 & 5 & 4 \\
BA & 3 & 0 & 0 & 2 & 3 \\
VA & 6 & 6 & 6 & 6 & 6 \\
EA & & & & & \\
\hline
\end{tabular}

Table 14: Number of rational bidders in periods 1-3 and 8-10.

session $1 \quad$ session $2 \quad$ session $3 \quad$ session $4 \quad$ session 5

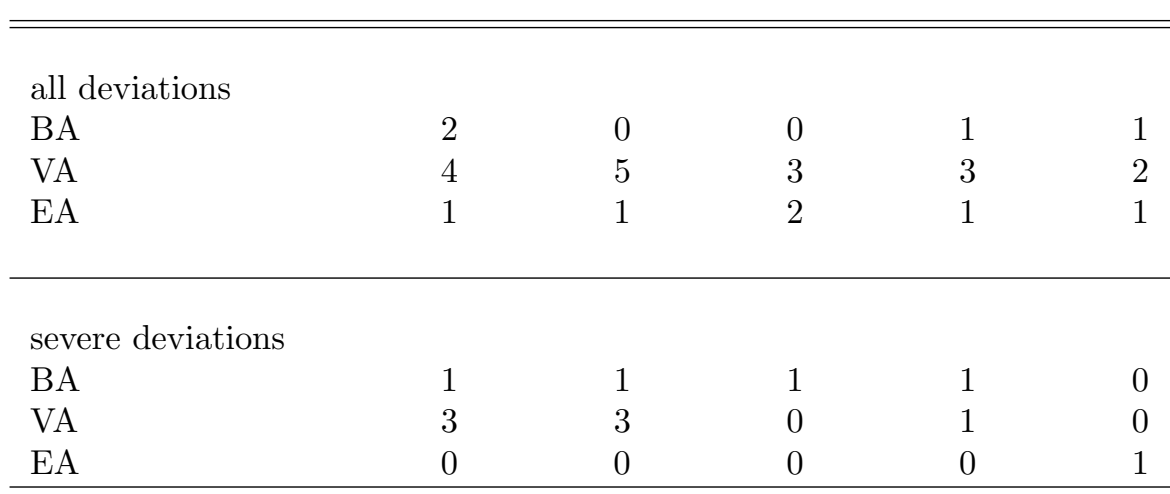

Table 15: Number of non-learners in periods 1-3 and 8-10. 


\begin{tabular}{lrrrrr}
\hline & session 1 & session 2 & session 3 & session 4 & session 5 \\
\hline \hline & & & & & \\
BA & 62.7 & 62.9 & 64.4 & 66.6 & 62.8 \\
VA & 60.6 & 67.5 & 62.7 & 66.3 & 63.6 \\
EA & 65.3 & 64.7 & 67.6 & 62.2 & 62.3 \\
\hline
\end{tabular}

Table 16: Average revenue of auctions.

\begin{tabular}{lrrrrr}
\hline & session 1 & session 2 & session 3 & session 4 & session 5 \\
\hline \hline & & & & & \\
BA & $53 \%$ & $60 \%$ & $47 \%$ & $53 \%$ & $47 \%$ \\
VA & $43 \%$ & $27 \%$ & $40 \%$ & $43 \%$ & $57 \%$ \\
EA & $43 \%$ & $73 \%$ & $63 \%$ & $63 \%$ & $57 \%$ \\
\hline
\end{tabular}

Table 17: Percentage of auctions with revenue at the predicted level.

\begin{tabular}{lrrrrr}
\hline & session 1 & session 2 & session 3 & session 4 & session 5 \\
& & & & & \\
\hline \hline & & & & & \\
BA & 4.77 & 3.51 & 3.87 & 5.63 & 3.43 \\
VA & 7.97 & 6.33 & 6.23 & 4.83 & 2.53 \\
EA & 4.83 & 1.53 & 1.97 & 3.07 & 2.71 \\
\hline
\end{tabular}

Table 18: Average difference between the resulting and the predicted revenue (in absolute value).

\begin{tabular}{lrrrrr}
\hline & session 1 & session 2 & session 3 & session 4 & session 5 \\
\hline \hline & & & & & \\
BA & $87.0 \%$ & $97.0 \%$ & $80.0 \%$ & $80.0 \%$ & $87.0 \%$ \\
VA & $90.0 \%$ & $67.0 \%$ & $83.0 \%$ & $87.0 \%$ & $100.0 \%$ \\
EA & $80.0 \%$ & $97.0 \%$ & $97.0 \%$ & $97.0 \%$ & $90.0 \%$ \\
\hline
\end{tabular}

Table 19: Percentage of auctions with the efficient allocation. 
session $1 \quad$ session $2 \quad$ session $3 \quad$ session $4 \quad$ session 5

\begin{tabular}{llllll}
\hline \hline & & & & & \\
BA & 3.00 & 0.17 & 1.73 & 1.60 & 1.43 \\
VA & 0.53 & 2.33 & 1.57 & 1.57 & 0.00 \\
EA & 1.23 & 0.20 & 0.43 & 0.20 & 1.07 \\
\hline
\end{tabular}

Table 20: Average loss of efficiency (in absolute value).

session $1 \quad$ session $2 \quad$ session $3 \quad$ session $4 \quad$ session 5

\begin{tabular}{llllll}
\hline \hline & & & & & \\
BA & $3.62 \%$ & $0.33 \%$ & $2.45 \%$ & $2.08 \%$ & $1.66 \%$ \\
VA & $0.83 \%$ & $3.28 \%$ & $1.89 \%$ & $1.94 \%$ & $0.00 \%$ \\
EA & $1.57 \%$ & $0.22 \%$ & $0.67 \%$ & $0.34 \%$ & $1.34 \%$ \\
\hline
\end{tabular}

Table 21: Average relative loss of efficiency. 